\title{
Nanoremediation and International Environmental Restoration Markets
}

\author{
Paul Bardos (paul@r3environmental.co.uk) ( $\mathrm{r}^{3}$ environmental technology ltd, Reading, UK) \\ Brian Bone ( $\mathrm{r}^{3}$ environmental technology ltd, Reading, UK) \\ Miroslav Cernik (Technical University of Liberec, Czech Republic) \\ Dan Elliott (Geosyntec Consultants, Princeton, New Jersey, USA) \\ Sarah Jones ( $\mathrm{r}^{3}$ environmental technology ltd, Reading, UK) \\ Corinne Merly (BRGM, Orleans, France)
}

\begin{abstract}
Nano-scale zero-valent iron (nZVI) is the most commonly used nanoremediation material. While there has been a reasonable level of application of nZVI technologies for in situ remediation in the USA, its utilisation across Europe has been much more limited. There has been significant uncertainty about the balance between deployment risks and benefits for nanoparticles (NPs) which has affected the regulatory position in several countries. Some Member States of the European Union (EU) take a strongly precautionary view of the risks from the deployment of NPs into the subsurface preventing the adoption of the technology. This paper provides a riskbenefit assessment for nZVI based on published information and describes the steps that will be taken by a major European research project (NanoRem), as part of its work, to provide a basis for better informed decision making in European environmental restoration markets. A key part of this process is dialogue between practitioners with researchers. NanoRem therefore has an active process of communication with different stakeholder networks (regulators, service providers and site owners). NanoRem hopes to stimulate a consensus on appropriate use of nanoremediation and so stimulate effective technology transfer to the European remediation market.
\end{abstract}

\section{INTRODUCTION}

The transfer of technology information from academia to business and vice versa, or from business to business, is vital to innovation and competitiveness in the environmental restoration industry. It is clear that successful international technology transfer requires an interdisciplinary approach that tackles all of these. A good example of the importance of this transfer process can be seen in the international market for nanoremediation in Europe.

Laboratory scale work implies nanotechnologies could offer a step-change in remediation capabilities: treating persistent contaminants, avoiding process intermediates and increasing the speed at which degradation or stabilisation can take place (Müller and Nowack 2010). In 2007 in Europe it was forecast that the 2010 world market for environmental nanotechnologies would be around \$6 billion (JRC Ispra 2007). However, in practice, adoption of nanoremediation has been slow. While some projects may have gone unreported in the technical literature, Bardos et al. (2011) identified just 58 examples of field scale applications of nZVI, which has expanded to 70 examples identified by NANOREM as of early 2014. Only 17 of these were in Europe (Czech Republic Germany and Italy), although bench-scale nanoremediation research is widespread across the EU. The majority of applications in the field were in situ injections of modified nZVI. From a commercial and practical standpoint this was largely as a niche technology for treating chlorinated solvents, competing with a range of alternatives.

Some of the reasons for the limited adoption of nZVI may relate to the nanomaterials themselves, with concerns about their relative cost, efficacy, and long-term effectiveness in 
contaminated environmental media (e.g. groundwater, sediments, etc.). Few organisations like to be the "first" to take on a technical risk. There are also some regulatory concerns regarding the implications of their deployment in the field, namely on potential human health and ecotoxicological effects resulting from exposure to these nanomaterials. The potential risks of the deployment of NPs for in situ remediation are poorly understood, leading to precautionary and conservative regulatory positions. For example, there has been a moratorium on the use of nanoremediation in the UK in response to the Royal Society/Royal Academy of Engineering report (Anon 2012, RS \& RAE 2004). A number of national risk-benefit studies have taken place, for instance in Austria, Belgium, Switzerland, UK and USA (Karn et al. 2009, OVAM 2006; Bardos et al. 2011, Bundesamt für Umwelt 2010, Grieger et al. 2010).

So in principle there are two substantive failures in technology transfer from academic laboratory scale studies to practical deployment in environmental restoration markets for nanoremediation: (1) limited penetration of technical opportunities to create substantial benefits over existing remedial alternatives in practice; (2) failure to convince sceptical regulatory and user stakeholders that NP deployment risks are acceptable and manageable.

\section{USE OF nZVI IN REMEDIATION}

In situ remediation techniques (exploiting biological, chemical, physical stabilisation and/or thermal processes) are being increasingly used to avoid excavation of materials or surface treatment of groundwater from "pump and treat" projects. The use of nanoparticles potentially extends the range of available in situ remediation technologies, and may offer particular benefits in some applications(Müller and Nowack 2010).

Zero valent iron (essentially finely ground iron) has been used as a treatment reagent in in situ remediation for many years, in particular for permeable reactive barriers (NATO/CCMS 1998). Nano-scale zero valent iron (nZVI) is a type of iron nanoparticle that has been investigated for deployment for in situ remediation, i.e. within the subsurface, as a groundwater and aquifer treatment. The first documented field trial of nZVI, in 2000, involved treatment of trichloroethylene in groundwater at a manufacturing site in Trenton, New Jersey, USA (Elliott and Zhang 2001).

Nanoparticles (NPs) are typically defined as particles with one or more dimension of less than $100 \mathrm{~nm}$. As a result of their size, nanoparticles can have markedly different physical and chemical properties compared with their bulk counterparts (RS \& RAE 2004), enabling them to be utilised for novel purposes, including the potential for use in remediation. However, whilst the possibility of unique characteristics gives nZVI promise for beneficial applications, it is simultaneously a cause of concern, as there is a degree of uncertainty with regards to nZVI particle behaviour, fate and toxicity.

\section{RISK BENEFIT ASSESSMENT FOR nZVI}

Potential Benefits of using nZVI in Remediation. The principal potential benefits of nZVI use that have led to its development, particularly in comparison to the use of conventional (granular or microscale) zero-valent iron are the extent and speed of contaminant degradation possible from nZVI. These result from the greater surface area (and therefore increased reactivity) of NPs (RS \& RAE 2004). nZVI is also considered to have a better potential to migrate in aquifers. Furthermore, there may be a potential extension of the range of treatable contaminants to include types traditionally seen as recalcitrant, for example, PCB and lindane (Bezbaruah et al. 2009, Kim et al. 2008, Singh et al. 2011). 
When compared to bioremediation, nZVI usage also offers a probable reduction in the formation of toxic intermediate products for the degradation of chlorinated ethenes (Bezbaruah 2009, Nurmi et al. 2005. Moreover, the overall evidence supports a view that nZVI has little, if any, deleterious effect on (and may possibly even stimulate) dehalorespiration, a key process in biological remediation (Kuang et al. 2013, Comba et al. 2011, Kirschling et al. 2010, Xiu et al. 2010). This potential stimulating effect is believed to result from the slow corrosion of nZVI in the aqueous medium in which it reduces water forming hydroxide $\left(\mathrm{OH}^{-}\right)$and hydrogen gas, the universal electron donor for anaerobic microbial processes. nZVI therefore has the potential for synergistic application with bioremediation techniques (Lacinová et al. 2013, Baiget et al. 2013).

As the active lifespan of nZVI is likely to be limited (owing to passivation and agglomeration - see below), the impacts on the receiving environment and ecology are likely to be reduced compared to other in situ remediation options.

Implementation Issues for nZVI. Ensuring efficient delivery of NPs in situ while guaranteeing sufficient reactivity of the NPs are the two major technical challenges for nZVI use. The high chemical reactivity of nZVI particles means that their abilities to react with contaminants and to move through the subsurface are limited by several processes within the sub-surface, namely:

- Agglomeration where NPs adhere together (Elliott 2010),

- Passivation where NP surfaces are chemically inactivated (Reinsch et al. 2010) although activity may remain within particles - and

- Sorption onto material within the aquifer (LQM 2014).

To help overcome these problems, and thus increase the usefulness of nZVI in remediation, a number of modifications to the nanoparticles have been developed, including: stabilisation, emulsification, and anchoring the particles to a supporting matrix (O'Carroll et al. 2013). In addition, bimetallic nanoparticles have been developed. These are also nZVI variants containing a small amount of a noble metal, such as palladium (typically less than 1\%) which acts as a catalyst, increasing both reaction rates and the range of treatable contaminants (e.g. Kim et al. 2008).

The processes limiting activity and mobility, combined with their typically high reactivity, means that the handling of nZVI products requires quite a lot of care. Handling needs to prevent the oxidation (and indeed for some products combustion) of nZVI on exposure to air. The design of both injection processes and an overall injection grid needs to take account of the relatively low mobility of nZVI in the subsurface and the high density of nZVI suspensions which affects how they are handled and pumped (e.g. Uyttebroek et al. 2010).

Treatment costs are contentious. Overall, cost-effectiveness for nZVI is likely to be specific to site circumstances and characterisation. The available evidence suggests that currently costs for nZVI are likely to be higher than microscale ZVI on a weight for weight basis. Perhaps nZVI has the potential to be more reactive, nZVI may be comparable to micro-ZVI in terms of cost in terms of actual remediation outcome, as less would be required for the same treatment impact. However, there are few reliable published cost and performance data currently available.

Potential Deployment Risks from nZVI Use. The perceived risks from nZVI use, as a part of general concerns over the environmental release of engineered nanoparticles, have led to a precautionary regulatory approach in many countries. However, such a stringent regulatory position is not well supported by the available documented evidence. 
As with many substances deployed into the subsurface by different in situ remediation techniques, the use of nZVI may pose risks to human health and the environment. In general risks depend on likely environmental fate, transport and toxicity of a substance.

In the case of nZVI research based on laboratory studies and the fate of naturally occurring iron NPs indicates that the fate of manufactured nZVI in an aquifer will be conversion into larger particles of iron (II) and (III) oxides/hydroxides, similar to naturally occurring minerals (O'Carroll 2013, Johnson et al. 2013, Reinsch et al. 2010, Gilbert et al. 2007). Transport of nZVI will be limited by processes of agglomeration and sorption, as well as its density, and the transport of unmodified nZVI will soon diminish as a result of processes of passivation (Reinsch et al. 2010). In broad terms there is an inverse relationship between reactivity and mobility; the most reactive particles agglomerate and sorb to surfaces more readily, reducing distance transported. If nZVI has been modified to increase mobility, it is likely to have lost a significant degree of reactivity to achieve this, meaning the particles which pose the greatest hazard in terms of reactivity are also the most easily contained.

Knowledge about direct effects of nZVI on human health, and other receptors, is limited. It has been suggested that for toxicity associated with NP size unique behaviours are only observed in iron Nps smaller than 30nm and that larger NPs can be considered analogous to bulk materials (Auffan et al. 2009). nZVI used in remediation is typically in the 10-100nm size range, as produced, (Karn et al. 2009, Müller \& Nowack 2010, Nurmi et al. 2005, O'Carroll et al. 2013), but tends to agglomerate to larger particles.

Laboratory studies have reported contradictory results with regards to the toxicity of nZVI. For example, nZVI toxicity to bacterial cells has been reported by in vitro studies above conventional ZVI (Li et al. 2010, Auffan et al. 2006, Macé et al. 2006). However, this was attributed to redox conditions. Other studies have reported no or mixed impacts of nZVI on soil and groundwater micro-organisms (Wang et al. 2012, Fajardo et al. 2013, Fajardo et al. 2012). For non-microbial soil and water organisms, such as collembola, ostracods and earthworms, some degree of toxic response to nZVI has been shown in laboratory experiments (El-Temsah and Joner 2013, 2012). However, toxicity was largely observed to reduce in magnitude over time, which was attributed to oxidation of the NPs.

The principal receptors of concern are likely to be groundwater and surface water, where this is in close proximity to the injection area, and their ecologies. Assuming that nZVI is deployed in the subsurface, where it remains, human health exposure pathways are likely to be limited those possible from occupational exposure. Appropriate measures should be in place relating to the manufacture and transport of nZVI, for example as defined in Material Safety Data Sheets, so occupational exposure scenarios are regarded as unlikely.

Hence, overall it appears that deployment risks from the use of nZVI are likely to be manageable. The available evidence (Phenrat et al. 2009, Liu \& Lowry 2006), which is mostly based on laboratory based data and/or modelling, indicates that their environmental persistence is relatively short (months) and nZVI's ability to travel is limited (metres). Indeed, it has been speculated that even modified nZVI is not likely to travel much farther than $100 \mathrm{~m}$ from an injection location (Saleh et al. 2008) and much shorter distances when site conditions limit mobility. Reports of field scale deployments of nZVI suggest that nZVI travels only a few metres from the injection point (Su et al. 2013, Uyttebroek et al. 2010, Tratnyek and Johnson 2006). However, there are too few well validated field studies of nZVI to draw firm conclusions about its mobility under realistic field conditions. 
Sustainability Considerations. Little work to date had been undertaken on assessing the sustainability of nZVI use in remediation, although some NGOs have raised questions about the sustainability of nano-material production (e.g. Friends of the Earth 2010), particularly its energy budget. On the other hand, nZVI offers certain aspects which could bring about sustainability gains over other remediation options. For example, nZVI may have a potentially lower impact on soil functionality compared with competing technologies (e.g. in situ heating or chemical oxidation). Nonetheless, certain elements also threaten to undermine opinions about the sustainability of the technology. These include concerns about the life cycle impacts of nZVI production and use and the intertwined issues of heightened risk perceptions and fear of nanotechnology, which potentially compromise social acceptance of nZVI use (Environment Agency 2006). It should be noted, however, that evidence for actual risks relating to nZVI is scant. Overall, whether or not nZVI demonstrates a sustainable in situ remediation option is likely to be largely based on site context and the suitability of the technology to the site in question.

Overall appraisal. nZVI is anticipated as having two major benefits for process based remediation, at least in theory: possible extension of the range of treatable contaminant types, and increasing the efficacy of treatment (speed and degree of completion). To date, the use of nZVI in remediation in practice is largely a niche application for chlorinated solvents in aquifers, competing with more established techniques such as in situ bioremediation, chemical reduction and ZVI (e.g. permeable reactive barriers). The majority of nZVI applications have taken place in North America, with a small number of applications in the field in mainland Europe and elsewhere.

At present nano-remediation may offer advantages in some applications, compared with other in situ remediation tools, but this will be highly dependent on site specific circumstances. In the medium to longer term nanoremediation could substantially expand the range of treatable land contamination problems.

The available evidence supports, but does not irrevocably confirm, a view that the risks of nZVI deployment should be considered in the same way as other potentially hazardous treatment reagents (such as persulphates).

A substantial impediment to the use of nZVI in remediation is the uncertain basis for understanding the risks of its deployment to the wider environment, in particular to groundwater and surface water receptors. Although most laboratory studies and subjective practitioner experience would suggest that adverse effects would be minor, localised and short-lived, there is a lack of effective particle monitoring technologies and peer reviewed and validated data from applications in the field that corroborates this view. This presents a significant challenge to regulatory acceptance which the NanoRem project seeks to address.

\section{NANOREM}

NanoRem (Taking Nanotechnological Remediation Processes from Lab Scale to End User Applications for the Restoration of a Clean Environment) is a research project, funded through the European Commission's Framework 7 research programme (www.nanorem.eu). It aims to advance the state of the art of nanoremediation by developing and strengthening the fundamental scientific underpinnings, applications, and implications of nanoremediation use in Europe. NanoRem focuses on facilitating practical, safe, economic and exploitable nanotechnology for in situ remediation. This is being undertaken in parallel with developing a 
comprehensive understanding of the environmental risk-benefit for the use of NPs, market demand, overall sustainability, and stakeholder perceptions. It is a $€ 14$ million international collaborative project with 28 Partners from 12 EU countries, and an international Project Advisory Group (PAG) providing linkages to the USA and Asia.

To achieve its overarching goals, the main components of NanoRem include technology development activities (to improve the offering of nanoremediation materials and deployment methods beyond its current market niche); laboratory based evaluation activities (to provide greater certainty about deployment risks and remediation performance); scale up and field based trials (to support proof of concept and provide well validated field based studies of NP activity, fate and transport) and modelling activities (to support field scale use of NPs). These activities, which collectively commenced in April 2013, are supported by dialogue and exploitation work that seeks to engage the major European stakeholder networks (industry, service providers, regulators) developing a broad consensus in Europe for the appropriate use of nanoremediation, and so build market confidence.

\section{NANOREM INFORMATION TRANSFER}

NanoRem has set itself the goal of achieving a step change in the development and use of nanoremediation technology in Europe. To reach this goal does not only depend on the creation of new research information, but also on the transmission to remediation practitioners and encouraging their use of that information. Therefore NanoRem is seeking to facilitate an international consensus in the European market amongst different stakeholders (regulators, site owners and service providers) on the appropriate use on NPs in remediation. Its strategy to achieve this aim depends on three strands working together in an integrated way:

- Evidence that addresses crucial gaps in knowledge

- Providing reliable research based information on nanoparticles and their properties (in particular related to fate, transport and ecological impacts),

- Providing tools to be able to better observe the behaviour of nanoparticles inground during practical use in the field,

- Testing our understanding of NP behaviour and remediation effectiveness in well instrumented large scale systems (circa $100 \mathrm{~m}^{3}$ tanks),

- Providing well documented and independently scrutinised case studies of field scale deployments, using the tools developed for field scale monitoring of NPs.

- Providing the right kind of evidence that is persuasive

- Subjecting evidence to review and scrutiny by an independent project advisory board and the various European stakeholder networks involved with contaminated land management (see below)

- Providing transparent approaches to the assessment of deployment risks in NanoRem case studies that are firmly supported by existing evidence and can be broadly regarded as best available practice for decision making on a panEuropean basis (and not just the national jurisdiction of where a trial takes place)

- Providing at least a qualitative understanding of the life cycle impacts of the production of NPs used in NanoRem case studies and a qualitative sustainability assessment of the nanoremediation used benchmarked against at least one possible alternative remediation strategy.

- Communicating the evidence and developing shared conclusions 
There are two well recognised stakeholder networks operating across Europe. The COMMON FORUM on Contaminated Land is a network of contaminated land policy makers, regulators and technical advisors from Environment Authorities in European Union member states and European Free Trade Association countries (www.commonforum.eu). The Network for Industrially Contaminated Land in Europe (NICOLE) is primarily a network of industrial problem holders and service providers, contractors and consultants (www.nicole.org). Along with the emerging sustainable remediation forums in several countries (Bardos et al. 2013), these provide a great opportunity for engagement and dialogue with practitioners, and a channel to rapid adoption for any consensus opinion found. Both NICOLE and COMMON FORUM are participants in the NanoRem PAG. In addition, NanoRem has begun a process to collate and present evidence in a way that these networks can use, with a view to developing a broader consensus in the medium term. It is envisaged by NanoRem that a shared opinion across NanoRem and these networks could be very persuasive to European remediation markets and their regulation.

NanoRem has begun by collating available published information as "information for decision makers" which is provided in a scaleable format on its web site, from simple "frequently asked questions" to more detailed "thematic pages" and then to comprehensive downloadable reports and links to other external information. This information is offered on a "without prejudice" basis to all practitioners, and is also serving as the basis for consultation documents with which to engage NICOLE, the COMMON FORUM and other stakeholder interests. It is hoped that these will serve as the foundation for a process of consensus building.

NanoRem is also needs to ensure that it is recognised to have taken a transparent and ethical approach to its deployment of NPs in the field, with deployment risk assessment following best available guidance. To this end it carried out an expert elicitation workshop and technical review over 2013 resulting in the development of a common protocol for case studies and their local stakeholders to follow for deployment risk assessment.

\section{RESULTS/LESSONS LEARNED}

After its first year, the initial outputs used in this engagement process comprising the risk-benefit assessment for nZVI summarised here, the deployment risks workshop and protocol and the information for decision makers is freely available on www.nanorem.eu and the process of engagement with stakeholder networks is underway.

The most significant lesson we have learned in this process of engagement is that large European endeavours take time and differences in culture and language (i.e. even when all speaking English) hamper understanding. However, taking an open and honest approach to presenting evidence and responding to opinions fosters trust and good collaborative working arrangements.

\section{ACKNOWLEDGEMENTS}

The research leading to these results has received funding from the European Union Seventh Framework Programme ([FP7/2007-2013] [FP7/2007-2011]) under grant agreement $n^{\circ}$ FP7-309517

\section{REFERENCES}

Anon 2012. 'Not enough evidence for nanotech clean-up'. ENDS Report 446, March 2012, p. 24, 26 March 2012 
Auffan, M., Decome, L., Rose, J., Orsier, T., De Meo. M., Briois, V., Chaneac, C., Olivi, L., Berge-Lefranc, J-L., Botta, A., Wiesner, M.R. and Bottero, J-Y. 2006. 'In vitro interactions between DMSA-coated maghemite nanoparticles and human fibroblasts: A physicochemical and cyto-genotoxical study', Environmental Science and Technology, 40(14): 4367-4373.

Auffan, M., Rose, J., Bottero, J. Y., Lowry, G. V., Jolivet, J. P., and Wiesner, M. R. 2009. 'Towards a definition of inorganic nanoparticles from an environmental, health and safety perspective'. Nature, 4: 634-641.

Baiget, M., Constantí, M., López, M. T., and Medina, F. (2013) 'Uranium removal from a contaminated effluent using a combined microbial and nanoparticle system' New Biotechnology, 30: 788-792.

Bardos, P, Bakker, L., Darmendrail, D., Harries, N., Holland, K., MacKay, S., Pachon, C., Slenders, H., Smith, G., Smith, J. and Wiltshire, L. 2013. 'Sustainable and green remediation - global update', Proceedings Aquaconsoil 2013 Barcelona, Spain. April 2013. www.aquaconsoil.org/AquaConSoil2013/Proceedings.html

Bardos, P., Bone, B., Elliott, D., et al. 2011. Risk/benefit approach to the application of iron nanoparticles for the remediation of contaminated sites in the environment - CB0440. Report for the Department of Environment, Food and Rural Affairs. http://randd.defra.gov.uk/Default.aspx?Menu=Menu\&Module=More \&Location=None \& Completed $=0 \&$ ProjectID $=17502$

Bezbaruah, A.N., Thompson, J.M. and Chisholm, B.J. 2009. 'Remediation of alachlor and atrazine contaminated water with zero-valent iron nanoparticles', Journal of Environmental Science and Health, Part B: Pesticides, Food Contaminants and Agricultural Wastes, 44: 518-524.

Bundesamt für Umwelt (2010) 'Noch viele Fragezeichen' (In German), Nanotechnologie, 3: 21$22 ; 24 ; 26-27 ; 30$.

Comba, S., Di Molfetta, A. and Sethi, R. 2011. 'A comparison between field applications of nano-, micro-,and millimetric zero-valent iron for the remediation of contaminated aquifers' Water, Air, and Soil Pollution, 215: 595-607.

Elliott, D.W. 2010. CLU-IN Webinar Presentation. Www.clu-in.org/conf/tio/nanoiron/prez/1280x1024/ppframe.cfm?date $=502$

Elliott, D.W. and Zhang, W-X. 2001. 'Field assessment of nanoscale biometallic particles for groundwater treatment', Environmental Science and Technology, 35: 4922-4926.

El-Temsah, Y. S., and Joner, E. J. 2013. 'Effects of nano-sized zero-valent iron (nZVI) on DDT degradation in soil and its toxicity to collembola and ostracods' Chemosphere, 92: 131137

El-Temsah, Y. S., and Joner, E. J. 2012. 'Ecotoxicological effects on earthworms of fresh and aged nano-sized zero-valent iron (nZVI) in soil' Chemosphere, 89: 76-82.

Environment Agency 2006. A people's inquiry on nanotechnology and the environment. Science Report SCHO0607BMUJ-E-P. Environment Agency, Bristol, UK. ISBN: 978-1-84432782-9; www.sciencewise-erc.org.uk/cms/assets/Uploads/Project-files/NanodialoguesApeoples-inquiry.pdf

Fajardo, C., Ortíz, L. T., Rodríguez-Membibre, M. L., et al. 2012. 'Assessing the impact of zerovalent iron (ZVI) nanotechnology on soil microbial structure and functionality: A molecular approach' Chemosphere, 86: 802-808. 
Fajardo, C., Saccà, M. L., Martinez-Gomariz, M., et al. 2013 'Transcriptional and proteomic stress responses of a soil bacterium Bacillus cereus to nanosized zero-valent iron (nZVI) particles'. Chemosphere, 93: 1077-1083.

Friends of the Earth (2010) Nanotechnology, climate and energy: overheated promises and hot air? : www.foe.co.uk/resource/reports/nanotechnology_climate.pdf

Gilbert, B., Lu, G. and Kim, C.S. 2007. 'Stable cluster formation in aqueous suspensions of iron oxyhydroxide nanoparticles', Journal of Colloid and Interface Science 313: 152-159.

Grieger, K. D., Fjordbøge, A., Hartmann, N. B., et al. 2010. 'Environmental Benefits and Risks of Zero-Valent Iron Nanoparticles (nZVI) for In Situ Remediation: Risk Mitigation or Trade-Off?' Journal of Contaminant Hydrology, 118: 165-183.

Johnson, R. L., Nurmi, J. T., et al. 2013. 'Field-scale transport and transformation of carboxymethylcellulose-stabilized nano zero-valent iron' Environmental Science \& Technology 47(3): 1573-1580.

Joint Research Centre - JRC (2007) Report from the Workshop onNanotechnologies for Environmental Remediation. JRC Ispra 16-17 April 2007. David Rickerby and Mark Morrison. www.nanowerk.com/nanotechnology/reports/reportpdf/report101.pdf

Karn, B., Kuiken, T. and Otto, M. 2009. 'Nanotechnology and in situ remediation: A review of the benefits and potential risks', Environmental Health Perspectives, 117: 1823-1831.

Kim, J-H., Tratnyek, P.G., Chang, Y-S. 2008. 'Rapid dechlorination of polychlorinated dibenzop-dioxins by bimetallic and nanosized zerovalent iron'. Environmental Science \& Technology 42: 4106-4112.

Kirschling, T.L., Gregory, K.B., Minkley, E.G., et al. 2010. 'Impact of nanoscale zero valent iron on geochemistry and microbial populations in trichloroethylene contaminated aquifer materials', Environmental Science and Technology, 44: 3474-3480.

Kuang, Y., Zhou, Y., Chen, Z., et al. 2013. 'Impact of $\mathrm{Fe}$ and $\mathrm{Ni} / \mathrm{Fe}$ nanoparticles on biodegradation of phenol by the strain Bacillus fusiformis (BFN) at various $\mathrm{pH}$ values' Bioresource technology, 136: 588-594.

Lacinová, L., Černíková, M., Hrabal and J., Černík, M. 2013. 'In-Situ Combination of Bio and Abio Remediation of Chlorinated Ethenes' Ecological Chemistry and Engineering, 20: 463-473.

Land Quality Management LTD - LQM 2014. Potential environmental risks of nanoparticle deployment NanoRem Deliverable 9.2.1 www.nanorem.eu

Li, Z., Greden, K., Alvarez, P.J.J., Gregory, K.B. And Lowry, G.V. 2010. 'Adsorbed polymer and NOM limits adhesion and toxicity of nano scale zerovalent iron to $E$. coli', Environmental Science and Technology, 44: 3462-3467.

Liu, Y.Q. and Lowry, G.V. 2006. 'Effect of particle age (Fe-o content) and solution pH on NZVI reactivity: H-2 evolution and TCE dechlorination'. Environmental Science \& Technology, 40: 6085-6090

Macé, C., Desrocher, S., Gheorghiu, F., et al. 2006. 'Nanotechnology and groundwater remediation: A step forward in technology and understanding', Remediation Journal, 16: 23-33.

Müller, N.C. and Nowack, B. 2010. Nano Zero Valent Iron - THE Solution for Water and Soil Remediation?, ObservatoryNANO Focus Report. www.observatorynano.eu/project/filesystem/files/nZVI_final_vsObservatory.pdf

NATO/CCMS 1998. Treatment Walls and Permeable Reactive Barriers. NATO/CCMS Pilot Study Evaluation of Demonstrated and Emerging Technologies for the Treatment of 
Contaminated Land and Groundwater (Phase III) 1998 Special Session Report number 229. Also US EPA report: EPA 542-R-98-003.

O'Carroll, D., Sleep, B., Krol, M., et al. 2013) 'Nanoscale zero valent iron and bimetallic particles for contaminated site remediation' Advances in Water Resources, 51: 104-122.

OVAM (2006) Injectie van (bi)metallisch nanoschaal ijzerpartikels in met chloorkoolwaterstoffen verontreinigde aquifers. (in Flemish) Fase 1:Literatuurstudie stand van de techniek. www.ovam.be/jahia/Jahia/pid/5

Phenrat, T., Liu, Y., Tilton, R.D. and Lowry, G.V. 2009. 'Adsorbed polyelectrolyte coatings decrease $\mathrm{Fe}^{0}$ nanoparticle reactivity with TCE in water: conceptual model and mechanisms', Environmental Science and Technology, 43: 1507-1514.

Reinsch, B.C., Forsberg, B., Penn, R.L., et al. 2010. 'Chemical transformations during aging of zerovalent iron nanoparticles in the presence of common groundwater dissolved constituents', Environmental Science and Technology, 44: 3455-3461.

Royal Society and Royal Academy of Engineering (RS/RAE) (2004) Nanoscience and Nanotechnologies: Opportunities And Uncertainties. Royal Society, London, UK. www.raeng.org.uk/news/publications/list/reports/Nanoscience_nanotechnologies.pdf

Saleh, N., Kim, H-J., Phenrat, T., et al. 2008 'Ionic strength and composition affect the mobility of surface-modified $\mathrm{Fe}^{0}$ nanoparticles in water -saturated sand columns.' Environmental Science \& Technology, 42: 3349-3355

Singh, R., Singh, A., Misra, V., And Singh, R. P. 2011. 'Degradation of Lindane contaminated soil using zero-valent iron nanoparticles' Journal of Biomedical Nanotechnology 7: 175176.

Su, C., Puls, R. W., Krug, T. A., et al. 2013. 'Travel Distance and Transformation of Injected Emulsified Zerovalent Iron Nanoparticles in the Subsurface During Two and Half Years' Water Research, 47: 4095-4106.

Tratnyek, P.G. and Johnson, R.L. 2006. 'Nanotechnologies for environmental cleanup', Nano Today, 1: 44-48.

Uyttebroek, M., Baillieul, H., Vermeiren, N., et al. 2010 'In Situ Remediation of a Chlorinated Ethene Contaminated Source Zone by Injection of Zero-valent Iron: From Lab to Field Scale' Proceedings of the $4^{\text {th }}$ International Symposium on Permeable Reactive Barriers \& Reactive Zones, July, 2010.

Wang, Q., Jeong, S. W., and Choi, H. 2012. 'Removal of trichloroethylene DNAPL trapped in porous media using nanoscale zerovalent iron and bimetallic nanoparticles: Direct observation and quantification'. Journal of hazardous materials, 213: 299-310

Xiu, Z., Jin, Z., Li, T., et al. 2010. 'Effects of nano-scale zero-valent iron particles on a mixed culture dechlorinating trichloroethylene', Bioresource Technology, 101: 1141-1146. 